\title{
Formação profissional e serviços de saúde mental no SUS: estudo sobre a inserção de egressos do Curso de Terapia Ocupacional da FMUSP
}

\author{
Interprofessional education and Mental Health \\ Services on the context of SUS: study about the in- \\ sertion of graduates of the Course of Occupational \\ Therapy - FMUSP
}

\author{
Elisabete Ferreira Mângia ${ }^{1}$, Melissa Tieko Muramoto², \\ Ana Lucia Marinho Marques ${ }^{2}$
}

MÂNGIA, E. F.; MURAMOTO, M. T.; MARQUES, A. L. M. Formação profissional e serviços de saúde mental no SUS: estudo sobre a inserção de egressos do Curso de Terapia Ocupacional da FMUSP. Rev. Ter. Ocup. Univ. São Paulo, v. 21, n. 2, p. 148-157, maio/ago. 2010.

\begin{abstract}
RESUMO: A implementação das redes de serviços de saúde mental configura-se como processo complexo que coloca exigências para o ensino de graduação. O curso de Terapia Ocupacional da FMUSP implementou mudanças curriculares tendo em vista a formação de profissionais comprometidos e capazes de compreender e lidar com as exigências teóricas e técnicas da atenção e da reabilitação psicossocial de pessoas com transtornos mentais. Objetivos: Conhecer, caracterizar e analisar a inserção de egressos em serviços e/ou projetos de saúde mental no contexto do SUS e analisar a adequação entre a formação e as exigências para a atuação profissional colocadas pelos novos serviços e/ou projetos de saúde mental. Método: Pesquisa qualitativa baseada em procedimentos da etnometodologia consistiu na realização de grupos focais, ao longo do segundo semestre de 2009, com egressos inseridos em serviços públicos de saúde mental. Resultados: dados obtidos demonstram que os egressos: conseguem inserção em serviços de saúde mental nos primeiros 6 meses de formados; buscam principalmente cursos de especialização e/ou aprimoramento; vivenciam grande rotatividade em serviços novos; relatam que tais serviços são heterogêneos em relação à organização, processo de trabalho, estrutura, gestão e objetivos assistenciais; são convocados ao desempenho de tarefas de planejamento e gestão sem que disponham de experiência e maturidade; relatam que os serviços são implantados sem um processo formativo e de gestão consistentes, enfrentam um cenário repleto de conflitos técnicos e teóricos que expressam dificuldades presentes no processo de mudança no campo da saúde mental. Conclusões: os novos cenários exigem novas competências profissionais não previstas na graduação; qualificação e formação permanente; mudanças na formação oferecida pela graduação especialmente nos campos da atenção básica, dependência química e alcoolismo. Há falta de formação para o trabalho em equipe e para a gestão e modelagem de serviços. Os jovens profissionais necessitam de respaldo institucional pois são os protagonistas das mudanças propostas pela Política de Saúde Mental.
\end{abstract}

DESCRITORES: Formação de recursos humanos; Serviços de saúde mental/recursos humanos; Sistema único de saúde; Terapia ocupacional/recursos humanos.

1. Prof $^{\mathrm{a}} \operatorname{Dr}^{\mathrm{a}}$ do Curso de Terapia Ocupacional da FMUSP.

2. Terapeuta Ocupacional do Departamento de Fisioterapia, Fonoaudiologia e Terapia Ocupacional da FMUSP.

Endereço para correspondência: Departamento de Fisioterapia, Fonoaudiologia e Terapia Ocupacional da FMUSP. Rua Cipotânea, 51, Cidade Universitária, São Paulo, SP. CEP 05360-160. 
MÂNGIA, E. F. et al. Formação profissional e serviços. Rev. Ter. Ocup. Univ. São Paulo, v. 21, n. 2, p. 148-157, maio/ago. 2010.

\section{INTRODUÇÃO}

A s necessidades das pessoas com transtornos mentais extrapolam o campo da saúde e requerem colaboração e parcerias entre diferentes setores, de forma que as redes de serviços de saúde mental comunitária devem organizar-se a partir da lógica intersetorial. Devem ainda buscar construir o cuidado baseado em evidências; a continuidade do cuidado em oposição ao cuidado episódico; a facilitação do acesso e o respeito às diferenças locais e regionais (WHO, 2003).

No Brasil, é ainda recente a implementação das redes de serviços de saúde mental comunitária e, apesar da grande expansão dos serviços baseados na comunidade, ainda são frágeis os recursos disponíveis para orientar sua modelagem, a capacitação das equipes e a produção de conhecimento nesse campo.

Percebe-se também grande dificuldade na manutenção e continuidade das experiências. A política pública de saúde se vê muito vulnerável diante das mudanças no poder executivo, pois a descentralização da gestão confere quase total autonomia ao poder municipal no que concerne à gestão, manutenção e ampliação ou desinvestimento em políticas de saúde mental.

Nesse contexto, têm faltado aos municípios capacidade de gestão, continuidade, documentação, reprodução e avaliação das experiências desenvolvidas no âmbito da saúde mental comunitária, além da imensa dificuldade no recrutamento, formação e capacitação dos recursos humanos necessários para a viabilização das propostas da Política de Saúde Mental.

Nota-se também, que as exigências colocadas pela nova Política, especialmente no que diz respeito à implementação de serviços de saúde mental na comunidade, não têm encontrado respostas adequadas no aparelho formador. Assim, os novos serviços não representam necessariamente fatores de proteção aos usuários contra os riscos da institucionalização ou da excessiva medicalização de problemas que mantém grande conexão com o contexto social, pois dependendo do estilo de trabalho que desenvolvem podem reproduzir a lógica que num primeiro momento visavam combater (MÂNGIA; MURAMOTO, 2009).

A qualificação dos serviços e equipes de saúde mental comunitária acoplada a estratégias consistentes de investigação, produção e sistematização de conhecimentos, se coloca como fator determinante para o êxito assistencial em saúde mental e sua sustentabilidade.

\section{OBJETIVOS}

Este estudo pretendeu conhecer, caracterizar e analisar a inserção de egressos do curso de terapia ocupacional da FMUSP em serviços e/ou projetos de saúde mental no contexto do Sistema Único de Saúde (SUS). Especificamente buscou descrever a trajetória de inserção profissional de alunos formados no período de 1999 até 2005 e analisar a adequação entre a formação proposta na graduação e as exigências para a atuação profissional colocadas pelos novos serviços e/ou projetos de saúde mental. O projeto obteve aprovação de Comitê de ética do Complexo FMUSP-HC, aprovado em 05/12/2007, sob protocolo Cappesq n ${ }^{\circ}$ 1050/07.

\section{PROCEDIMENTOS METODOLÓGICOS}

A pesquisa foi desenvolvida em duas fases. A primeira consistiu na identificação de concluintes do curso de terapia ocupacional da FMUSP do período de 1999 até 2005 por meio de pesquisa documental no setor de alunos do Departamento de Fisioterapia, Fonoaudiologia e Terapia Ocupacional. Para esse grupo foi enviado um questionário para identificação da área de atuação. Foram selecionados aqueles que se encontravam inseridos na área de saúde mental e especialmente em serviços públicos. Esse grupo foi convidado a participar da segunda fase da pesquisa, que consistiu na realização de grupo focal.

Aceitaram o convite 8 profissionais com os quais foram realizados 2 encontros com 2 horas de duração cada um. As sessões foram gravadas e transcritas. Adotou-se metodologia convencional para organização, condução, documentação e análise de grupo focal (BARBOUR, 2009).

De acordo com as proposições da teoria fundamentada, o material textual foi submetido inicialmente ao processo de codificação aberta, de forma a dar visibilidade à reflexão promovida nos grupos e manter maior proximidade com os pontos de vista dos participantes sobre o processo de ingresso nos serviços de saúde mental e sobre as suas necessidades formativas. Num segundo momento, o material selecionado foi submetido ao processo de codificação seletiva, o que resultou em agrupamentos temáticos mais abrangentes que pudessem sintetizar a primeira codificação (FLICK, 2009).

Os dados e respectiva análise foram assim agrupados: I. processo de entrada nos serviços; II. características dos serviços e demandas profissionais e III. formação e prática profissional.

I Processo de Entrada nos Serviços

Abrange a inclusão do profissional na equipe e a definição de seus papéis gerais e específicos. Observou-se 
MÂNGIA, E. F. et al. Formação profissional e serviços. Rev. Ter. Ocup. Univ. São Paulo, v. 21, n. 2, p. 148-157, maio/ago. 2010.

que os recém formados conseguem inserção nos serviços de saúde mental ao longo dos primeiros 6 meses após o término da graduação. $\mathrm{O}$ início do desenvolvimento dos papéis profissionais não é construído a partir de processos formais de tomada de conhecimento sobre o projeto institucional, ou de capacitação que ofereçam ao recém ingresso elementos orientadores para a prática futura. Ao contrário, ocorre a partir da imersão do profissional na prática e do contato com a cultura da equipe, que passa ao novo membro sua experiência e expectativas.

Apenas nas equipes dos Núcleos de Apoio á Saúde da Família (NASF), foram relatados processos de formação que antecederam a entrada do novo trabalhador no campo.

(...) na primeira semana houve capacitação (...), sobre o processo da região, diretrizes do PSF (...), visitamos todas as unidades para conhecer as equipes, as dinâmicas e as principais necessidades.

Tais processos foram avaliados como positivos, embora qualificados como frágeis, por não oferecerem recursos suficientes para orientar a prática cotidiana. Considerou-se também que os novos profissionais são convocados muito rapidamente a escolherem seus locais de inserção, sem que se sintam seguros para isso.

"Senti o processo um pouco solto (...) partimos para conhecer o território, as instituições de outros setores (...) e a rede que vai dar suporte ao nosso trabalho. Conversamos (...) sobre a prática do matriciamento e iremos instaurar um fórum de trabalhadores da região".

Os relatos mostraram que é frequente que jovens profissionais, ou mesmo recém formados, participem do processo de inauguração de serviços e início de desenvolvimento das práticas assistenciais, sem que para isso sejam devidamente orientados.

"Sou a primeira TO do CAPS, que abriu em fevereiro desse ano [2008] (...) serviço é novo e foi inaugurado antes da equipe ser montada (...). Inicialmente havia apenas uma psicóloga e a coordenadora [municipal] de saúde mental".

\section{Características dos Serviços e Demandas} Profissionais

Os relatos mostraram que os serviços que compõem a rede de saúde mental são muito heterogêneos entre si em diversos aspectos:

\section{A) Tipo de serviço e organização do trabalho}

Foram relatadas experiências desenvolvidas nos seguintes serviços e/ou ações de saúde mental: Centros de Atenção Psicossocial (CAPS) adulto, Álcool e Drogas (AD) e infantil; Centros de Convivência (Ceccos); enfermaria psiquiátrica em hospital geral; equipes de NASF e/ou ações de matriciamento junto a equipes de atenção básica (desenvolvido por equipe de CAPS) e um serviço destinado a crianças e adolescentes em situação de vulnerabilidade. A despeito da heterogeneidade, o grupo apresentou pontos em comum sobre diversos aspectos que definem a organização de tais serviços.

Primeiramente, houve consenso de que as possibilidades de organização dos serviços e o seu perfil de ofertas são definidos pela forma de relação que cada equipe estabelece com a demanda. Considerou-se, com unanimidade, que os serviços assumem demanda excessiva e tentam, por si, criar estratégias para equacionar as carências da rede de serviços.

O CAPS responde a uma área de abrangência de 600 mil habitantes e temos mais de 400 matriculados. Na minha referência tenho 130 pessoas. Eu e uma auxiliar de enfermagem... desses 130, eu não sei quem são todos. ... É angustiante".

Percebe-se que a idéia de sobrecarga não vem problematizada em relação à posição dos serviços quanto à definição de prioridades, o que gera atribuições impossíveis de serem respondidas, como a do exemplo acima.

A inexistência ou falta de suporte adequado da rede também afeta a possibilidade de resposta dos serviços e gera incertezas nas equipes. Aponta também para a falta de definição sobre o projeto institucional e a responsabilização pela demanda em cada um deles.

"Esse NASF [foi organizado para atender] principalmente a saúde mental, mas na região não há serviços de referência. A princípio, o foco do trabalho será o matriciamento em saúde mental. Agora se vai ser de fato, não sabemos".

"Quando entrei havia triagem individual, mas [devido ao excesso de usuários] (...) a coordenadora não queria fechar a porta, (...) passamos a fazer acolhimento em grupo (...) cheguei a fazer o acolhimento em grupo de 11 pessoas".

\section{B) A centralidade do trabalho em equipe}

Outro ponto em comum diz respeito ao trabalho em equipe multiprofissional. Embora com diferenças e ainda na presença do modelo tradicional e hierárquico, prevalece o modelo, de organização do trabalho em equipe, horizontal, participativo e colaborativo. 
MÂNGIA, E. F. et al. Formação profissional e serviços. Rev. Ter. Ocup. Univ. São Paulo, v. 21, n. 2, p. 148-157, maio/ago. 2010.

"[No serviço] as áreas são circunscritas, cada um está dentro da sua área. (...). A primeira pessoa a atender é o psiquiatra e depois a criança passa em avaliação com os demais profissionais. (...) cada um faz a avaliação em sua área e indica o atendimento [especifico]".

"Depois da visita [domiciliar] tem a reunião da equipe para apresentação e discussão de casos novos".

"O acolhimento também é feito pela dupla de referência [todos os profissionais compartilham essa atividade”].

Neste aspecto se pode aferir um dos grandes avanços da política de saúde mental, que tem influenciado o conjunto do campo da saúde. As equipes se organizam a partir de encontros e reuniões de caráter técnico-administrativo e aquelas que envolvem as subdivisões das equipes para o trabalho assistencial e comunitário, Foram citadas reuniões: clínicas, administrativas, para discussão de casos, interunidades, intersetoriais, supervisões e as reuniões de referência. Nesses espaços, ocorrem trocas de informações, definições de práticas, planejamento e avaliação das situações vividas no cotidiano.

Considerada importante para a organização do trabalho em equipe, os processos de supervisão relatados mostraram diferentes modelos e abordagens. A principal diferença verificada esteve na definição sobre os participantes: toda a equipe ou apenas os profissionais de nível universitário. Verificou-se que a tendência mais aceita pelos participantes defende a importância da participação de toda a equipe (incluindo também o pessoal de apoio e administrativo), o que representa importante mudança para a cultura organizacional das equipes.

“(...), nós queríamos que a supervisão fosse só com os técnicos, porque é chato, a gente tratar de assuntos que não convém que muitos saibam (...) conversamos e [o supervisor] falou: 'olha, a medida que as pessoas trabalham aqui, elas também são operadoras de saúde mental e elas tem que estar inseridas na dinâmica do funcionamento do serviço'. Então a equipe começou a bancar que todos (...) participassem".

\section{C) População atendida}

Os serviços atendem a populações distintas. Em CAPS e enfermarias em hospitais gerais, ocorre a atenção a pessoas maiores de 18 anos; nos CAPS AD ocorre a atenção específica a adultos que fazem uso prejudicial de álcool e outras drogas e nos CAPS infantil a atenção a crianças e adolescentes. Nos serviços de atenção básica e equipes de NASF, a atenção é oferecida a toda a população de referência. De um modo geral, os depoimentos não contemplaram descrições mais precisas sobre a população atendida.
"No CAPS tem concentração maior de crianças com transtorno mental, muito mais autismo, neuroses, psicoses, um grau de comprometimento um pouco maior".

"No [serviço especializado] são crianças em situação de vulnerabilidade extrema, não necessariamente com algum tipo de transtorno psiquiátrico (...). Em situação de violência, $80 \%$ está em situação de abrigamento".

\section{humanos \\ D) Gestão, estrutura, recursos materiais e}

Foram identificadas diferenças em relação à forma de gestão, estrutura, recursos humanos e materiais de que dispõem cada serviço. Os recursos humanos forma identificados como o fator que mais compromete ou facilita o desenvolvimento do trabalho, não apenas em relação a presença ou ausência de equipes completas, mas também no que diz respeito ao capital cultural e técnico dos profissionais. Há grande rotatividade de profissionais e a falta mais notada é a de psiquiatras. Para os profissionais, a formação desempenha papel importante no desenvolvimento de ações adequadas ao modelo proposto, capazes de responder às prioridades assistenciais de cada território.

"A gente tem hoje duas psicólogas, uma assistente social (que pediu exoneração e outra ainda não foi contratada), um enfermeiro, eu como TO, (...) desde o início a equipe está sem psiquiatra".

Em relação aos contratos profissionais, houve o questionamento sobre o impacto da obrigatoriedade dos contratos de, no máximo, 30 horas semanais para terapeutas ocupacionais. Ficou claro que tal medida, ao invés de proteger os profissionais os obriga, a assumirem dois vínculos, o que os sobrecarrega. Viu-se que a redução da carga horária não foi acompanhada de valorização salarial. Além disso, há o impacto causado pela diferença de carga horária em relação aos demais profissionais.

\footnotetext{
"Acho importante falar sobre a carga horária, porque isso interfere na prática. No CAPS sou contratada para 20 hemanais".

"Faço 20h, mas acho muito ruim, porque tenho a obrigação de ir todo dia (...) 4 h, (...) capto a realidade de modo totalmente fragmentado, não consigo acompanhar uma atividade inteira. Todas as reuniões de PSF acontecem de manhã e eu estou alocada para ir à tarde (...)".

"Faço 30h, (...) não acompanho a chegada dos pacientes e há atividades que acontecem só de manhã e eu não estou lá. A gente tem uma equipe muito escassa e à tarde tem dias que fico sozinha como técnica".
} 
MÂNGIA, E. F. et al. Formação profissional e serviços. Rev. Ter. Ocup. Univ. São Paulo, v. 21, n. 2, p. 148-157, maio/ago. 2010.

Os salários mostram grande variação. Os salários mais baixos geram acordos internos de redução de carga horária, o que também deve ser identificado como um aspecto negativo da atual gestão de recursos humanos na saúde.

\footnotetext{
"Sou contratada por 30h, mas tenho um acordo no qual tenho um abono de $15 \%$ e, então, eu faço $25 h$ ".

"Sou contratada para 30h, mas tenho um acordo de redução de carga horária”.
}

Outro aspecto importante é que, especialmente no município de São Paulo, muitos serviços estão sob gestão de organizações sociais. Esse processo de terceirização vulnerabiliza o caráter público dos serviços e cria diferenças entre profissionais contratados pela gestão municipal e aqueles com vínculo com as organizações sociais. Os profissionais relataram que não há regulação dessa situação por parte do poder municipal o que contribui para o desgaste das equipes.

"Agora (...) quem ganhou os direitos da região foi a [OS], em abril ou março eles entrarão e nós não sabemos muito bem como vai ficar".

A problematização sobre os recursos materiais recaiu sobre o acesso aos recursos necessários ao desenvolvimento de atividades. Os relatos mostraram grande variação de recursos. Os serviços identificados como os que dispõem de recursos adequados são os que estão sob gestão de organização social e aquele ligado a um grande hospital de ensino.

"No CAPS infantil é complicado. Os brinquedos têm dois anos. Os jogos, um ano mais ou menos (...). Não tem manutenção".

"[por estar sob gestão de uma OS] não parece ser um serviço do SUS, em termos da verba (...) e facilidades que temos para fazer reformas e ter materiais. As coisas acabam acontecendo com agilidade. a a gente acaba esquecendo como era a burocracia".

\section{E) Perfil da oferta assistencial}

Os profissionais citaram o amplo conjunto de procedimentos desenvolvidos nos serviços e que configuram o perfil da oferta em cada um deles. Foram citadas: triagem, acolhimentos de recepção, plantões de acolhimento, atendimentos individuais, atendimentos das referências, visita domiciliar, atendimentos individuais e grupais para familiares e matriciamento.
Foram relatadas diversas modalidades de atendimentos grupais: verbal, com outros profissionais (psicólogo, fonoaudiólogo, farmacêutico, etc.), com oficineiros e pessoal de apoio, grupo de TO, oficinas de diversos tipos, atividades artísticas, corporais, grupos de inclusão no trabalho, grupos fechados e abertos, grupos de acolhimento, grupo de cidadania e assembléias. As práticas dos serviços incluem também palestras e discussões com outros serviços.

Observou-se que os grupos tendem a ter condução multiprofissional. No caso da definição das equipes e/ ou profissionais de referências (aqueles que assumem a responsabilidade específica pelo acompanhamento de cada sujeito), também ficou clara a presença da integração multiprofissional na definição de duplas, trios ou equipes e a inclusão de profissionais de nível médio e de apoio.

Houve pouco detalhamento sobre o conjunto de procedimentos citados e não se nota correlação clara entre o amplo espectro de procedimentos e sua integração às necessidades dos usuários e a definição sobre o desenvolvimento de projetos terapêuticos singulares. Também não foi possível observar nos relatos como se dá a participação dos usuários nessas diversas proposições.

Nesse contexto se pode considerar como ponto positivo a disseminação de novas práticas que incluem toda a equipe e ajudam a criar uma linguagem comum entre seus membros, a exemplo das práticas de acolhimento e grupos com coordenação conjunta. Contudo, apesar do trabalho em equipe ser a característica central da maior parte dos serviços, especialmente a partir dos procedimentos grupais, não há definições formalizadas sobre esses processos. Cada equipe cria seu próprio repertório a partir dos recursos de que dispõe, sem apoio formativo necessário ou indicações objetivas sobre o modelo de organização dos serviços, aspecto que deveria caber ao gestor.

Percebeu-se a falta de subsídios para justificar as estratégias adotadas e a visão genérica sobre os procedimentos ilustra isso. Pode-se problematizar também o repertório que os profissionais trazem da graduação e que se mostra mais frágil para orientar a atenção a determinadas populações: crianças com transtornos mentais severos, em grave risco social, com deficiência mental e/ou autismo. O mesmo se coloca para a abordagem de pessoas que fazem uso prejudicial de álcool e outras drogas, para as ações de matriciamento e para as ações de saúde mental na atenção básica. São campos de expansão dos serviços públicos, para os quais ainda não há respostas suficientes na formação universitária e, nem tampouco, nos processos de educação permanente.

Observou-se que as equipes vivem certo isolamento 
MÂNGIA, E. F. et al. Formação profissional e serviços. Rev. Ter. Ocup. Univ. São Paulo, v. 21, n. 2, p. 148-157, maio/ago. 2010.

e o estilo de cada serviço é extremamente dependente das características específicas de suas respectivas equipes, sem a necessária mediação externa, que deveria ser desenvolvida pelos gestores.

\section{F) Centralidade das oficinas}

$\mathrm{Na}$ maior parte do grupo esteve presente o questionamento sobre a demanda pela realização de oficinas como um procedimento exigido aos terapeutas ocupacionais, talvez mais fortemente que aos demais profissionais. Os participantes apresentaram críticas ao modelo de serviço orientado por procedimentos e especialmente, no caso dos CAPS, centrados na oferta de oficinas como um recurso que preenche a maior parte do tempo de usuários e técnicos.

"Entrei para substituir uma TO que só fazia oficinas. [o pedido da equipe] Era -entre e ocupe o lugar dela e faça o que ela já fazia".

“(...) meu primeiro movimento foi tentar entrar na equipe (...) tinha uma coisa muito forte com oficinas (...) Tudo era oficina (...), as oficinas preenchiam a grade (...) Isso me angustiava muito".

Se, por um lado, ao romper com a lógica tradicional da assistência, o desenvolvimento de oficinas surgiu como inovação do modelo assistencial proposto pela política de saúde mental. Por outro, se coloca como um "artefato" que preenche, na maioria dos serviços, a fragilidade na definição do modelo assistencial e dos procedimentos adequados às necessidades dos sujeitos atendidos, especialmente os casos mais graves e/ou complexos. A preocupação dos profissionais, cuja formação ofereceu novo repertório para o trabalho em saúde mental, se justifica e exige um processo de reflexão e formação, junto às equipes, para a transformação dessa demanda e criação de outras possibilidades de intervenções.

“(....) Comecei com as oficinas (...), o que era complicado (...) eram oficinas muito fechadas e longe daquilo que os pacientes traziam como demandas".

"(...) [o serviço] está num momento de diminuir as oficinas para os profissionais poderem ter tempo para os usuários".

“(...) havia uma expectativa grande quanto à TO (...) 'Agora vamos organizar as oficinas, agora tudo vai melhorar!'. Essa era a idéia, a de que a TO iria salvar as oficinas".

A inclusão em práticas que o profissional discorda se coloca como um fator de desgaste e cria muitas contradições. Requer grande esforço junto às equipes para que sejam adotadas outras perspectivas, mais adequadas ao que preconiza o novo modelo, especialmente no que diz respeito ao trabalho centrado nas necessidades dos usuários e inserido no contexto territorial.

\section{G) Atividades de gestão e planejamento}

A expansão da rede de serviços de saúde mental não tem sido acompanhada pela disponibilidade de profissionais mais experientes para ocuparem papel na gestão e coordenação. Diante disso, os novos profissionais têm sido convocados ao desempenho de tarefas de planejamento e gestão sem que disponham de experiência e maturidade suficientes.

“(...) assim que entrei no CAPS [infantil], depois de alguns meses, já assumi a direção ... saí há mais ou menos um ano".

Nos CAPS AD, essa situação é particularmente agravada pela falta de referenciais e modelos de abordagem. As equipes devem criar seus próprios referencias e ao mesmo tempo assumirem responsabilidades pela implantação e organização dos novos serviços, o que envolve as questões assistenciais, a própria constituição da rede de serviços, e o desenvolvimento de atividades educativas na comunidade, dentre outras.

\footnotetext{
"A gente vai sendo convocado para pensar o projeto terapêutico do serviço, como organizar os projetos terapêuticos dos usuários (...) pensar a conexão com as outras secretarias, e outros equipamentos [tudo]”.

"A questão de álcool e drogas é um enigma, as pessoas não sabem como agir e aí acionam o serviço para irmos tirar dúvidas (...) temos pensado em projetos de capacitação das equipes na atenção básica (...), Nos convidaram para irmos às escolas. Acho que tem essas frentes, a de atendimento em grupo ou individual, e a organização do serviço",
}

As equipes são sobrecarregadas por tarefas de planejamento e adequação dos serviços e podem ou não assumir tais encargos. É um equilíbrio complicado de responsabilização. Falta presença de uma gestão que integre e contribua nos processos de modelagem e formação dos serviços. As equipes são deixadas à mercê de sua própria inciativa e capacidade organizativa. Assumir a direção de serviços implica também em grande sobrecarga de trabalho e, muitas vezes, significa acumular tarefas de gestão e assistência.

"Enquanto estive na direção, passei por periodos em 
MÂNGIA, E. F. et al. Formação profissional e serviços. Rev. Ter. Ocup. Univ. São Paulo, v. 21, n. 2, p. 148-157, maio/ago. 2010.

que ficava no Caps quarenta horas, todos os dias (...), passei por periodos em que ficava trinta e dessas trinta fazia atendimentos e dividia com a direção. Aí cheguei no limite [passei a fazer] as vinte as vinte na direção e sai dos atendimentos".

\section{Formação e prática profissional}

Conteúdos presentes na graduação foram considerados norteadores para pensar e realizar a prática profissional. Foram citados como importantes: os conceitos de saúde como direito; o SUS, seus princípios, diretrizes e as proposições sobre rede de serviços; as políticas e programas de saúde, especialmente aqueles voltados para a população com transtornos mentais severos, adulta e infanto-juvenil, e as voltadas para a população que apresenta transtornos decorrentes do uso prejudicial de álcool e outras drogas. Conteúdos importantes para o trabalho em saúde: trabalho em equipe; processos de gestão; território; integralidade, projetos terapêuticos e o trabalho em grupo. Também foram mencionados conteúdos compreendidos como ferramentas para a prática, contemplados nas disciplinas de atividades e recursos terapêuticos.

\section{A) A formação para o trabalho no SUS}

O estudo sobre o SUS, seus princípios e diretrizes, programas e serviços e especialmente a relação com os usuários foi considerado um dos pontos mais importantes da graduação.

"A gente teve muito de SUS, entender os princípios do SUS, entender o que é o CAPS dentro da hierarquia dos serviços públicos, qual é a função".

"[a importância de] entender a saúde como direito... isso foi da graduação".

Esta compreensão foi considerada um diferencial na formação que, por vezes, coloca o profissional, egresso da USP, em posição de multiplicador deste conhecimento para o restante da equipe, produzindo discussões e reflexões sobre o serviço e a prática, além de, em algumas situações, conduzi-los a posição de gerentes e coordenadores do serviço.

“(...) acho que não se tinha essas discussões até a minha chegada, tenho essa impressão de que as pessoas iam fazendo (...) vamos abrir um CAPS, então vamos visitar outros CAPS ADs, e fazer assim, porque os outros CAPS fazem, mas não por entender que isso é uma política, que existem diretrizes do Ministério [da Saúde], que a meta é a atenção integral".

\section{B) A Reforma Psiquiátrica e a Política de Saúde Mental}

A apropriação sobre a história e os referenciais teórico-práticos da Reforma Psiquiátrica no Brasil foi outro aspecto considerado importante na graduação. Considerado conteúdo principal para a prática em saúde mental também foi avaliado como um diferencial para a inserção nas equipes.

Avaliou-se que, o envolvimento com esses conteúdos, desde a graduação, tende a impulsionar os jovens profissionais para uma prática compromissada com a construção e efetivação da Política Nacional de Saúde Mental. Propicia a formação de profissional capaz de compreender e lidar com as exigências teóricas e técnicas da atenção e da reabilitação das pessoas com transtornos mentais em seus contextos de vida.

Os relatos mostraram que, em sua maioria, os profissionais recém-formados ingressam em serviços da rede pública e que tal ingresso é uma escolha implicada com os princípios do SUS e da Reforma Psiquiátrica.

\begin{abstract}
"Muitas pessoas vão para um CAPS porque param lá. (...) A gente está num CAPS porque escolhemos estar num CAPS. Estamos em num CAPS porque queremos construir uma perspectiva de CAPS, então isso só foi possível pela formação que tivemos em saúde mental".
\end{abstract}

Assim, se compreende que parte do papel a ser desempenhado nos serviços extrapola as ações específicas do terapeuta ocupacional. Os profissionais descreveram como parte das suas ações cotidianas: a defesa do acesso dos usuários a serviços de qualidade, o papel de multiplicadores desse conhecimento junto aos outros profissionais das equipes e a própria construção da rede de saúde mental comunitária.

"É um trabalho que desgasta, mas aprendemos que esse trabalho com a equipe também faz parte do nosso trabalho. Porque faz. (...) acho que, de repente, outros profissionais podem (...) ir lá e fazer o seu trabalho dentro da sala e Ok. Acho que a nossa formação tem um olhar crítico em relação a isso (...)”.

\section{C) Contribuição das disciplinas específicas}

Os participantes também identificaram outros conteúdos da graduação que consideram importantes na construção de suas práticas. Dentre eles estão os oferecidos nas disciplinas de atividades e recursos terapêuticos (ARTs), que ofereceram recursos, especialmente para o manejo de grupos, modalidade de atendimento central nos serviços. 
MÂNGIA, E. F. et al. Formação profissional e serviços. Rev. Ter. Ocup. Univ. São Paulo, v. 21, n. 2, p. 148-157, maio/ago. 2010.

"Eu lembro muito das ARTs, que [tivemos] no processo de formação, (...) eram espaços bem potentes, que possibilitavam a gente vivenciar muita coisa".

“(...) acho que a questão de trabalhar em grupos, de pensar o trabalho em grupos, é um ponto importante também da nossa formação".

Também foram valorizadas as disciplinas de práticas e estágios supervisionados, que possibilitaram o contato com as populações atendidas em diferentes serviços. Os participantes afirmaram que foi possível articular as experiências e conhecimentos produzidos em práticas vivenciadas junto a populações com outras problemáticas para o trabalho no campo da saúde mental.

\begin{abstract}
"Fiz bolsa-trabalho na Associação Minha Rua Minha Casa, (...) e acho que foi uma experiência muito importante para pensar a questão do campo social, [e da] interface com o campo da saúde mental e com os serviços da rede pública.".
\end{abstract}

\section{D) Atenção aos usuários de álcool e outras drogas}

Com a recente ampliação dos serviços específicos para a população que apresenta algum tipo de problemática decorrente do uso de álcool e outras drogas, observa-se o aumento da inserção de terapeutas ocupacionais nesses serviços. Os relatos mostraram que os profissionais consideram que não foram preparados na graduação para o trabalho nesse campo.

No entanto, considerou-se que a graduação desenvolveu a base de formação em saúde mental comunitária, o que permitem conexões com todo o campo de atenção em saúde mental. A formação voltada para o SUS e para a perspectiva da atenção comunitária prepara os profissionais para a compreensão do tipo de trabalho a ser desenvolvido nos diversos serviços.

\begin{abstract}
"Acho que, num primeiro momento, me senti um pouco desamparada pela graduação quando fui parar num Caps Álcool e Drogas (...). Mas acho que, ao mesmo tempo, apesar de não saber as especificidades da população atendida neste serviço, (...) algumas questões norteadoras vão possibilitando e construindo a prática (...). Então, chego no serviço sem entender da população, mas entendendo muito do serviço".
\end{abstract}

\section{E) Necessidades formativas}

Os profissionais identificaram carências formativas na graduação e tendem a desenvolver processos formativos que visam suprir tais lacunas. Os participantes já realizaram ou estavam inseridos em processos de pós-graduação (lato e estrito senso), com exceção de um.

Dentre as necessidades formativas consideradas importantes para a prática, foram apontadas: noções de psicopatologia, psicodiagnóstico e farmacologia. Estes conteúdos foram julgados importantes por dois aspectos: o primeiro, em relação ao processo de acompanhamento dos usuários e no manejo das famílias. O segundo diz respeito a uma necessidade percebida de apropriação destes conteúdos para comunicar-se com os demais profissionais da equipe, especialmente com os médicos.

"No caso do CAPS infantil, todos os profissionais são muito cobrados em relação ao diagnóstico diretamente pelos pais (...)".

“(...) a medicação é usada como forma de contenção química. Então, se eu tenho um princípio de não contenção, eu preciso saber o que o cara está fazendo".

Os participantes afirmaram a importância do desenvolvimento de processos de formação continuada e educação permanente que possibilitem as trocas e a discussão e reflexão sobre a prática.

\footnotetext{
“(...) a gente precisa desse espaço para poder pensar junto, estudar, refletir, produzir sobre o que estamos fazendo. Sinto falta de espaços permanentes em que os TOs possam pensar suas práticas e refletir sobre elas de maneira conceitual".
}

Apontou-se também a carência de processos de formação para o SUS construído para e por diversos profissionais, com o intuito de estabelecer uma linguagem comum e compartilhada. Além disso, considerou-se importante que este processo seja pensado a partir da realidade local. A interprofissionalidade também foi considerada fator importante em tais processos.

\footnotetext{
"quando fico pensando outros espaços de formação (...) a primeira coisa que acho legal é a gente poder pensar diversas categorias profissionais diferentes numa mesma formação"

"Uma das coisas que acho é que as formações teriam que ser regionalizadas, senão não tem potência transformadora".
}

\section{CONSIDERAÇÕES FINAIS}

Os aspectos apresentados mostram que as redes de serviços de saúde mental estão em ampliação e diferenciação 
MÂNGIA, E. F. et al. Formação profissional e serviços. Rev. Ter. Ocup. Univ. São Paulo, v. 21, n. 2, p. 148-157, maio/ago. 2010.

o que coloca questões para a formação na graduação e para a educação permanente. Embora se possa reconhecer que a formação oferecida pela FMUSP é adequada. Há necessidades a serem respondidas pela Universidade, nos campos da graduação, da especialização e da educação permanente.

Apesar de conseguirem rápida inserção, os egressos vivem grande instabilidade decorrente das dificuldades encontradas nos serviços. Há grande rotatividade de profissionais e os serviços são muito heterogêneos entre si, quanto ao processo de trabalho, estrutura, gestão e objetivos assistenciais. Os egressos enfrentam um cenário repleto de fragilidades e conflitos técnicos e teóricos que expressam as dificuldades e desafios presentes no processo de mudança no modelo assistencial.

Viu-se que os egressos têm desempenhado tarefas de planejamento e gestão sem que disponham de formação, experiência e maturidade. A formação de caráter interprofissional ainda não se coloca como pauta para os cursos de graduação e é na prática cotidiana que se constroem os novos papeis profissionais. Os egressos se ressentem pela falta de processos de formação que antecedam ou acompanhem sua inserção nos serviços.

Os novos serviços se diferenciam por segmento populacional atendido e pelo nível de complexidade, exigem portando novas competências profissionais não previstas na graduação; qualificação e formação permanente.

Viu-se a necessidade de propor mudanças na formação oferecida pela graduação especialmente nos campos da atenção básica, dependência química e alcoolismo e gestão se de serviços. Há também a necessidade de aprimorar a formação para o uso de recursos teóricos e instrumentos mais estruturados para o planejamento, acompanhamento e avaliação de projetos terapêuticos, capazes de superar a organização de trabalho centrada em procedimentos e a banalização sobre a proposição de oficinas.

Não foram citadas necessidades formativas no campo do apoio a familiares e construção de redes sociais, mas estes parecem ser também campos importantes para o investimento formativo.

O estudo requer aprofundamento no que diz respeito aos perfis específicos de exigência dos distintos serviços que compõem a rede, mas já mostra indicações claras que podem orientar inovações na graduação. Os jovens profissionais necessitam de respaldo institucional pois são os protagonistas das mudanças propostas pela Política de Saúde Mental.

MÂNGIA, E. F.; MURAMOTO, M. T.; MARQUES, A. L. M. Interprofessional education and Mental Health Services on the context of SUS: study about the insertion of graduates of the Course of Occupational Therapy - FMUSP. Rev. Ter. Ocup. Univ. São Paulo, v. 21, n. 2, p. 148-157, maio/ ago. 2010. Rev. Ter. Ocup. Univ. São Paulo, v. 21, n. 2, p. 148-157, maio/ago. 2010.

\begin{abstract}
The implementation of mental health services network implies in a complex process, which places demands to the undergraduate education. The course of Occupational Therapy of FMUSP implemented curricular changes, considering the education of professionals compromised and able to comprehend and deal with theoretical and technical demands of the psychosocial rehabilitation of people with mental disorders. Objectives: to know, characterize and analyze the insertion of graduates working at services and/or projects of mental health in the context of SUS and to analyze the adequacy between the undergraduate education and the demands to the professional practice placed by the new services and/or projects of mental health. Method: Qualitative research based in ethnomethodological procedures consisted at the realization of focus groups, during 2009' second half, with graduates working at public services of mental health. Results: data show the graduates start working at mental health services during the first 6 months after graduation; search for post graduation courses; experience great turnover of professionals in new services; report heterogeneity related to the services organization, work process, structure, management and care objectives; are called to perform tasks of planning and management without experience and maturity; report the implantation of services without any educational and managerial consistent process; face a scenario full of technical and theoretical conflicts that express difficulties at the changing process in the field of mental health. Conclusions: new scenarios demand new professional competencies, which are not provided by the undergraduate education, especially those related to primary care, chemical dependency and alcoholism. There is a lack of education to prepare to team work and to services management and modeling. The new professionals need institutional support, once they are the protagonists of the proposed changes by the Mental Health Policy.
\end{abstract}

KEY WORDS: Human resources formation; Mental health services/manpower; Unified health system; Occupational therapy/manpower. 
MÂNGIA, E. F. et al. Formação profissional e serviços. Rev. Ter. Ocup. Univ. São Paulo, v. 21, n. 2, p. 148-157, maio/ago. 2010.

\section{REFERÊNCIAS}

BARBOUR, R. Grupos focais. Porto Alegre: Artmed, 2009.

FILCK, U. Introdução à pesquisa qualitativa. Porto Alegre: Artmed, 2009.

MANGiA, E. F.; MURAMOTO, M. T. Modelo de matriz: ferramenta para a construção de boas práticas em saúde mental comunitária. Rev. Ter. Ocup. Univ. São Paulo, v. 20, n. 2, p. 118-125, 2009.

WHO. Organization of Services For Mental Health. Mental Health Policy and Service Guidance Package. 2003. Disponível em: http:/ www.who.int/mental_health/resources/en/Organization.pdf 